Research Article

\title{
Exploration of PPP Investment and Financing Model for Infrastructure: A Case Study of the Beijing-Tianjin-Hebei Region
}

\author{
Xiuxiang Chi and Liguo Liu \\ School of Business, Beijing Union University, Beijing 100025, China \\ Correspondence should be addressed to Liguo Liu; liguo.liu@buu.edu.cn
}

Received 2 September 2021; Accepted 15 November 2021; Published 15 December 2021

Academic Editor: Daqing Gong

Copyright ( 2021 Xiuxiang Chi and Liguo Liu. This is an open access article distributed under the Creative Commons Attribution License, which permits unrestricted use, distribution, and reproduction in any medium, provided the original work is properly cited.

With the overall weakening of the macroeconomic situation, the investment growth in Beijing-Tianjin-Hebei continued to slow down. This article focuses on the reform and innovation of investment and financing models in the vertical and horizontal collaborative construction of Beijing-Tianjin-Hebei infrastructure. Under the framework of the PPP model, this article discusses how to design a market-oriented platform of infrastructure investment and financing model, introduce and use private capital, build remote capital access and exit mechanism, measure the government's financial capacity and financial risks in the PPP model, set up PPP institutions, and improve relevant laws and regulations to make the infrastructure construction and operation more efficient, thus promoting the coordinated development of infrastructure construction in the Beijing-Tianjin-Hebei region.

\section{Introduction}

The PPP (public-private partnership) investment and financing model is conducive to making up the funding gap in infrastructure construction and improving the efficiency of infrastructure construction and operation. This model has been implemented in foreign countries for nearly two centuries, and the relevant studies are relatively sufficient. The introduction of the PPP model in China is relatively late, and related studies are gradually deepening. According to the proposal at the Fifth Plenum of the 18th Central Committee of the Communist Party of China, the concept of innovative, coordinated, green, open, and shared development must be firmly established and practically implemented, which is a profound transformation related to the overall development of China $[1,2]$.

1.1. The Studies on PPP Investment and Financing Model Applications. Since the concession period from construction to operation of infrastructure, PPP projects last for several decades, and a lot of time is needed to negotiate in the early stage; the applications of PPP are extremely complicated from the economic and legal perspectives [3]. In terms of PPP application studies, one type of literature theoretically analyzes the necessity and feasibility of PPP model applications in China. Zhang et al. [4] believe that the key to PPP applications in China lies in the smooth formulation, implementation, and supervision of the contract between the private and public sectors. Tang and Zhou [5] analyzed and discussed the necessity and feasibility of the PPP model of public-private cooperation in China's rail transit industry. Sun et al. [6] studied the PPP optimal ownership structure model in highway projects. Xia and Zheng [7] and $\mathrm{Hu}[8]$ examined the benefit distribution of the PPP model. Qi [9], Sun [10], and Lin et al. [11] studied the risks of the PPP model. Some scholars [12, 13] learned the performance indicators of the PPP model, and others $[14,15]$ studied the government incentives of the PPP model.

1.2. The Studies on PPP Investment and Financing Model Cases. Another type of literature discusses the applications of the PPP model in China from the case analysis. Wang [16] analyzed the approval process, evaluation, and bidding of the Chinese BOT projects, taking the Laibin Power Plant B 
project as an example. Sun [17] took the North China Power Plant BOT project as an example to analyze the difficulties of implementing BOT in China and gave some suggestions on the effective project management. Chen [18] took the Chendu Water Plant B project as an example and pointed out five factors affecting the feasibility of the BOT project. Yuan [19] analyzed 15 factors that promote the development of China's transportation PPP project from the perspective of the public sectors, taking the PPP project of Beijing Metro Line 4 as an example [20].

Based on the theoretical analysis and experience summaries, this article aims to clarify the power and responsibilities between the central and local government, and between the government and social capital. Thus, the investment and financing model obstacles can be eliminated in the process of the coordination of infrastructure construction in the Beijing-Tianjin-Hebei region. The basic responsibility and risk undertaking model between the government and private organizations can be built, and a set of reform and innovation plans about investment and financing model can be formed [21,22].

\section{Literature Review}

Some intensive studies on the PPP model have been made overseas, and there are also more and more related researches in China. With the rapid advancement of China's infrastructure PPP investment and financing reforms, it is essential and urgent to further enrich and improve the related studies by combining the characteristics of China's infrastructure investment and financing with the spirit of the 19th National Congress of the Communist Party of China [23]. Specifically, the following two aspects are included.

Some key questions need to be answered, such as how to construct private capital access and exit mechanism? How to improve the infrastructure pricing mechanism? How to build a government compensation mechanism? How to measure the government's financial capacity and financial risks under the PPP model? Studies on these issues are conducive to promoting China's PPP model [24, 25].

One type of research on the efficiency of PPP has been carried out in the context of the "New Public Management" movement [26]. Although there are significant differences between the privatization of public services and PPP, the "New Public Management" movement, which aims to improve the efficiency of the public sector, provides a theoretical background for the PPP [27]. The new general management theory advocates that the government withdraws from the more efficient public service projects offered by the private sector because the introduction of competition will bring about better services and lower costs to citizens and, at the same time, reduce the waste of economic resources.

It is necessary to summarize PPP experience at home and abroad systematically. Most of the existing studies conduct empirical analysis from the perspective of a single case, and the conclusions of this type of research are typical but not universal. Therefore, the subsequent research should summarize the domestic and foreign experience in different infrastructure systems [28]. It should not only focus on successful cases but also conduct a more intensive study of failure cases to provide knowledge for China to promote the reform of infrastructure PPP [14].

Limited fiscal funds and insufficient budget are the main reasons the government invites the private sectors to participate in the construction and operation of infrastructure financing [29]. On the one hand, the government introduces the PPP model to infrastructure projects, saving financial resources [30]. On the other hand, the government can use the PPP model to hide government liability [31]. The research by Hammami and Ouhibi [32] shows that PPP is more commonly used in countries where the government is suffering from heavy liability burdens.

In addition, the lack of government management resources and the low efficiency of public services can also explain why the government invites the private sector to participate in infrastructure investment and financing [33]. The PPP model can take advantage of advanced technology and management experience in the private sector to improve infrastructure management and efficiency [34]. Grimsey and Lewis [35] also believe that PPP can solve the problems, such as a lot of cost overruns and delays in traditional government procurement methods for infrastructure, by building appropriate incentives between contracting partners. It is also conducive to stimulating innovation [11].

Another type of research on PPP from the perspective of efficiency is based on contract theory. Hart [36] believes that contracting cost is an essential factor in choosing PPP. When the quality of construction is difficult to measure accurately, but the quality of service can be better defined in the initial contract, PPP is superior to traditional investment and financing models. Bentz [37], based on contract theory, and Martimort and Pouyet [38], based on the moral hazard model, analyzed PPP and concluded that the PPP investment and financing model is more efficient than the traditional one.

Although foreign studies on the PPP model are mature, some fundamental theoretical issues are still to be addressed. The relatively prominent investment and financing problems of infrastructure construction in Beijing-Tianjin-Hebei and its solution mechanism's "natural experiment" provide a typical sample to observe and study the related issues. Based on the Chinese-style infrastructure construction and investment and financing management system [39], the indepth research on the PPP investment and financing model of infrastructure construction to solve the problem of the applicability of the theory has crucial theoretical value for enriching and improving the research on the PPP model of infrastructure construction $[6,40]$.

\section{Research Framework}

At present, with the overall weakening of the macroeconomic situation, the growth of investment in BeijingTianjin-Hebei continues to slow down. This research focuses on the reform and innovation of investment and financing models in the vertical and horizontal collaborative construction of Beijing-Tianjin-Hebei infrastructure (see 
Figure 1). Under the framework of the PPP model [41], this article discusses how to design a market-oriented platform of infrastructure investment and financing model, how to introduce and use private capital, how to build remote capital access and exit mechanism, how to measure the government's financial capacity and financial risks in the PPP model, and how to set up PPP institutions and improve relevant laws and regulations to make the infrastructure construction and operation more efficient [42], thus promoting the coordinated development of infrastructure construction in the Beijing-Tianjin-Hebei region.

3.1. Public and Private Capital Access and Exit, Equity Allocation, and Central and Local Authority Division. The PPP model is how the public and private capital build partnerships to provide public products and services. This partnership must deal with three issues. The first issue is creating an access and exit mechanism; the second is equity allocation; the third is the central and local authority [42]. This research will examine how to break through the public and private capital investment and financing barriers from the perspective of partnerships. This research will help build the PPP regional collaborative partnership for infrastructure construction [43].

To promote the reform of the PPP model, it is necessary to build a benefit-sharing mechanism, which is a critical issue that determines whether the PPP model is efficient.

\subsection{The Construction of Mechanisms, Such as Public and Private Win-Win Incentives, Pricing, Compensation, and So $o n$. The key to constructing a benefit-sharing mechanism is to form a public-private win-win incentive structure [44, 45]. Infrastructures are quasi-public goods, users can generally be charged, and the infrastructure pricing mechanism is benefit-sharing. For most infrastructures, fees cannot cover all costs, so the government must construct a corresponding financial compensation mechanism and government pro- curement mechanism.}

3.3. Risk Identification, Allocation, and Transfer in PPP Projects. To promote the reform of the PPP model, it is necessary to build a risk-sharing mechanism to achieve symmetry between returns and risks. Participants of $\mathrm{PPP}$ - private capital and the government - face a series of threats in the project implementation process. To build a risk-sharing mechanism, firstly, the risks should be identified. In addition, the risk allocation mechanism should be designed according to different types of hazards. Finally, the impact of risk transfer on risk sharing during the implementation process should be examined [46].

\section{Research Methods}

The research methods used in this article include the literature review method, field visits, statistical analysis, comparative analysis, and mathematical model analysis method. The characteristics of the investment and financing management system in our country based on the PPP model build a basic model of responsibilities and risk undertaking between the government and private organizations in terms of infrastructure construction [4].

4.1. Literature Review Method. This article systematically studies the related theory on the domestic and foreign investment and financing of the infrastructure construction, reviews the existing literature from the government-led and market-oriented aspects [47], and lays a theoretical foundation for the subsequent analysis. In addition, this article also compares traditional infrastructure investment and financing models and PPP investment and financing models from the perspective of efficiency and reviews the related literature.

Through field visits to Development and Reform Commission, Ministry of Finance and the government, and some relevant departments in Beijing, Tianjin, and Hebei, the relevant information and data about infrastructure investments have been obtained [48], and we have learned about the main approaches of PPP investment and financing innovation of infrastructure around Beijing, Tianjin, and Hebei.

4.2. Field Visits and Statistical Analysis. By analyzing the information and data, the problems with the investment and financing of Beijing-Tianjin-Hebei infrastructure have been summarized.

4.3. Comparative Analysis. In this, we investigate foreign infrastructure PPP investment and financing models, analyze the development process and main characteristics of the typical national PPP models, and summarize the experience of PPP investment and financing system innovation in various countries.

4.4. Mathematical Model Analysis Method. This article studies the characteristics of the investment and financing management system in our country based on the PPP model and builds a basic model of responsibilities and risk undertaking between the government and private organizations in terms of infrastructure construction.

After the initial responsibility and risk sharing, due to the complexity of internal and external risks and the uncertainty of the environment, some risks cannot be determined based on the principle of risk sharing and other qualitative indicators. For the unshared risks, the TOPSIS method is introduced to carry out the secondstage risk sharing. TOPSIS is the abbreviation of Technique for Order Preference by Similarity to Ideal Solution. Hwang and Yoon initially proposed it. It is a commonly used method in multiobjective decision analysis. When compared and tested with other multiattribute methods, one of its advantages is that it can quickly identify the best choice. It also has the advantages of simplicity and 


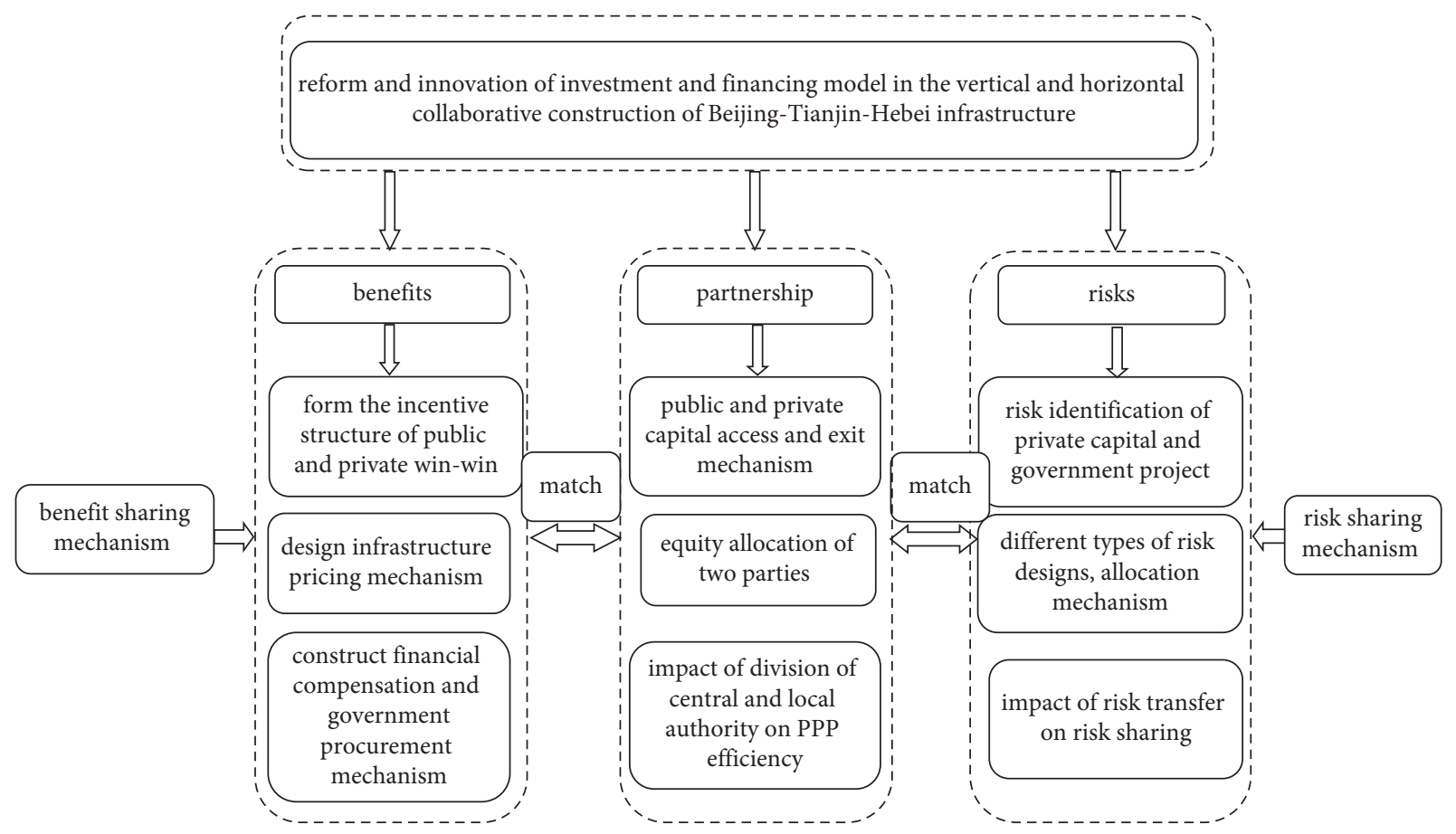

Figure 1: Research framework.

intuitiveness, scientific and reasonable calculation principles, etc. It does not require harsh data and can solve decision-making problems that involve fewer data and information. Specific steps are as follows.

Build $n$ risk evaluation criteria and the standardized decision matrix of $m$ risk-sharing parties:

$$
D=\left[\begin{array}{cccc}
x_{11} & x_{12} & \ldots & x_{1 n} \\
x_{21} & x_{22} & \ldots & x_{2 n} \\
\vdots & \vdots & & \vdots \\
x_{m 1} & x_{m 2} & \ldots & x_{m n}
\end{array}\right]=\left[\begin{array}{c}
D_{1}\left(x_{1}\right) \\
D_{2}\left(x_{2}\right) \\
\vdots \\
D_{m}\left(x_{n}\right)
\end{array}\right] .
$$

After normalization processing of feature matrix, we obtain the normalized vector $r_{i j}$ and build the normalized matrix about normalized vector $r_{i j}$.

$$
r_{i j}=\frac{x_{i j}}{\sqrt{\sum_{i=1}^{n} x_{i j}^{2}}}, \quad i=1,2, \ldots, n, j=1,2, \ldots, m .
$$

By calculating the weight normalized value $r_{i j}$, we build the weight normalization matrix about the weight normalized value $r_{i j}$.

$$
V_{i j}=W_{i j} \cdot R_{i j}, \quad i=1,2, \ldots m, j=1,2, \ldots, n .
$$

The weight determination methods used in the ASPbased dynamic alliance manufacturing resource evaluation model include the Delphi method, logarithmic least square method, analytic hierarchy process, etc. Among them, $w_{j}$ is the weight of the $j$-th index. Determine the ideal solution $A^{*}$ and the anti-ideal answer $A^{-}$according to the weight normalized value $v_{i j}$ :

$$
\begin{aligned}
A^{*} & =\left(\min _{i} v_{i j} \mid j \in J_{1}\right),\left(\min _{i} v_{i j} \mid j \in J_{2}\right), \mid i=1,2, \ldots, m \\
& =v_{1}^{*}, v_{2}^{*}, \ldots, v_{j}^{*}, \ldots, v_{n}^{*}, \\
A^{-} & =\left(\min _{i} v_{i j} \mid j \in J_{1}\right),\left(\min _{i} v_{i j} \mid j \in J_{2}\right), \mid i=1,2, \ldots, m \\
& =v_{1}^{-}, v_{2}^{-}, \ldots, v_{j}^{-}, \ldots, v_{n}^{-},
\end{aligned}
$$

where $j_{1}$ is the profitability index set, representing the optimal value on the $i$-th index, and $j_{2}$ is the loss index set, which means the worst deal on the $i$-th index. The larger the profitability index is, the more favorable it is to the evaluation result; the smaller the loss index is, the more advantageous it is to the evaluation result. On the contrary, it is unfavorable to the evaluation result.

Calculate the distance scale, that is, calculate the distance from each target to the ideal and anti-ideal solutions. The distance scale can be calculated by the $n$-dimensional Euclidean distance. The distance from the target to the perfect solution $A^{*}$ is $S^{*}$, and the distance to the anti-ideal solution $A^{-}$is $S^{-}$:

$$
\begin{aligned}
& S^{*}=\sqrt{\sum_{j-1}^{n}\left(V_{i j}-v_{j}^{*}\right)^{2}}, \quad i=1, \ldots, m, \\
& S^{-}=\sqrt{\sum_{j-1}^{n}\left(V_{i j}-v_{j}^{-}\right)^{2}} \quad i=1, \ldots, m,
\end{aligned}
$$

where $v_{j}^{*}$ and $v_{j}$ are spared, respectively, from the $j$-th target to the optimal target and the worst target; $v_{i j}$ is the weight 
normalized value of the $i$-th target and the $j$-th evaluation index; and $S^{*}$ is the proximity of the various evaluation targets and the optimal target. The smaller the value of $S^{*}$ is, the closer the evaluation target is to the ideal target and the more optimal the solution is.

Calculate the proximity of the ideal solution $C^{*}$ :

$$
C_{i}^{*}=\frac{S_{i}^{-}}{S_{i}^{*}+S_{i}^{-}}, \quad i=1,2, \ldots, m .
$$

In this formula, $0 \leq C_{i}^{*} \leq 1$. If $C_{i}^{*}=0, A_{i}=A^{-}$, indicating that the target is the worst; if $C_{i}^{*}=1, A_{i}=A^{*}$ indicates optimal target. In actual multitarget decision making, the possibility of the optimal target and the worst target is minimal.

According to the value of $C^{*}$, the evaluation targets are arranged in ascending order. $C^{*}$ represents the closeness of the sorting result. The larger the $\mathrm{C}^{*}$ value is, the better the target is, and the largest $C^{*}$ value is the optimal bid evaluation target.

There are two weighting methods for weights: subjective methods and objective methods. The unique approach determines the weight only according to the decision maker's preference or judgment and then applies mathematical techniques such as the eigenvector method, weighted least square method, and mathematical programming model to calculate. The objective approach automatically solves the mathematical model without considering the decision maker's preferences, suitable for situations where it is challenging to obtain weighted data, and subjective data are reliable [49].

After the initial risk sharing of this project, take the risks of market demand as an example to carry out secondary risk sharing: score the five aspects of financing, rate of return, profit margin, market preference, and market competition, respectively, represented by $\mathrm{A}, \mathrm{B}, \mathrm{C}, \mathrm{D}$, and $\mathrm{E}$. The process of using the TOPSIS model is as follows.

As shown in Table 1, five experts were invited to score and obtain the arithmetic average and then perform standardization processing to get a standardized matrix.

4.4.1. Determining Relative Proximity. Table 2 shows the relative proximity.

4.5. Result. In the end, Table 2 shows the relative proximity obtained: social capital > financial institution $>$ public organization. It is most appropriate for the social capital to bear the market demand risk to achieve the maximum economic benefits. Therefore, the TOPSIS method is used to share the remaining chances of the project [49].

Based on the risk sharing in the above cases, the primary responsibility and risk-sharing model for infrastructure projects under the PPP model is built. After the project database is used to identify the project responsibility risks, the project risk-sharing principles and relevant laws and regulations are used to carry out preliminary risk sharing for the project risk sharing. After the initial risk sharing, the TOPSIS method is used to carry out secondary risk sharing
TABLE 1: Standardized matrix.

\begin{tabular}{lccccc}
\hline Liability risk index & $\mathrm{A}$ & $\mathrm{B}$ & $\mathrm{C}$ & $\mathrm{D}$ & $\mathrm{E}$ \\
\hline Public organization & 1.0938 & 0.9064 & 1 & 1.1944 & 0.9786 \\
Social capital & 0.7813 & 1 & 0.9356 & 1 & 1 \\
Financial institutions & 0.7813 & 0.9489 & 0.8306 & 1.0256 & 0.8061 \\
$H_{j}$ & 0.9878 & 0.9993 & 0.9915 & 0.9971 & 0.9970 \\
$W_{j}$ & 0.77 & 0.03 & 0.31 & 0.45 & 0.11 \\
\hline
\end{tabular}

TABLE 2: Relative proximity.

\begin{tabular}{lcccc}
\hline Liability risk index & $x^{+}$ & $S^{+}$ & $S^{+}$ & $C^{*}$ \\
\hline Public organization & 0.0035 & 0.0388 & 0.0271 & 0.4115 \\
Social capital & 0.0054 & 0.0176 & 0.0393 & 0.6893 \\
Financial institutions & 0.0095 & 0.0395 & 0.0231 & 0.5187 \\
\hline
\end{tabular}

for the risks not shared by the project. As for the risk-sharing in dispute, the risk compensation price can be proposed by the risk bearer. The risk-sharing parties, sharing methods, and risk management are finalized through the tripartite contract negotiation.

4.6. Discussion and Conclusions. Based on the theoretical analysis and experience summaries, this article aims to clarify the power and responsibilities between the central and local government, and between the government and social capital. Thus, the investment and financing model obstacles can be eliminated in the process of the coordination of infrastructure construction in the Beijing-TianjinHebei region. The basic responsibility and risk undertaking model between the government and private organizations can be built and a set of reform and innovation plans about investment and financing model can be formed. Those plans are conducive to the vertical and horizontal collaborative construction of the Beijing-Tianjin-Hebei infrastructure [50].

(1) The research perspective has a certain degree of novelty. Most domestic studies on the PPP model are carried out from the standpoint of administrative cooperation. We believe that an important factor hindering the formation of a long-term mechanism for investment and financing of Beijing-Tianjin-Hebei infrastructure construction is the country's existing unreasonable infrastructure investment and financing management system. This research will explore these institutional factors and study the PPP model mechanism in the infrastructure construction of BeijingTianjin-Hebei under the new development concept.

(2) Infrastructure investment and financing based on government investment, bank loans, and debt financing are unsustainable. In recent years, the investment and financing model supported by land finance, state-owned investment, and platforms of funding as the main body and government investment, bank loans, and debt financing as the main ways has promoted the rapid development of infrastructure construction. However, as the local debt 


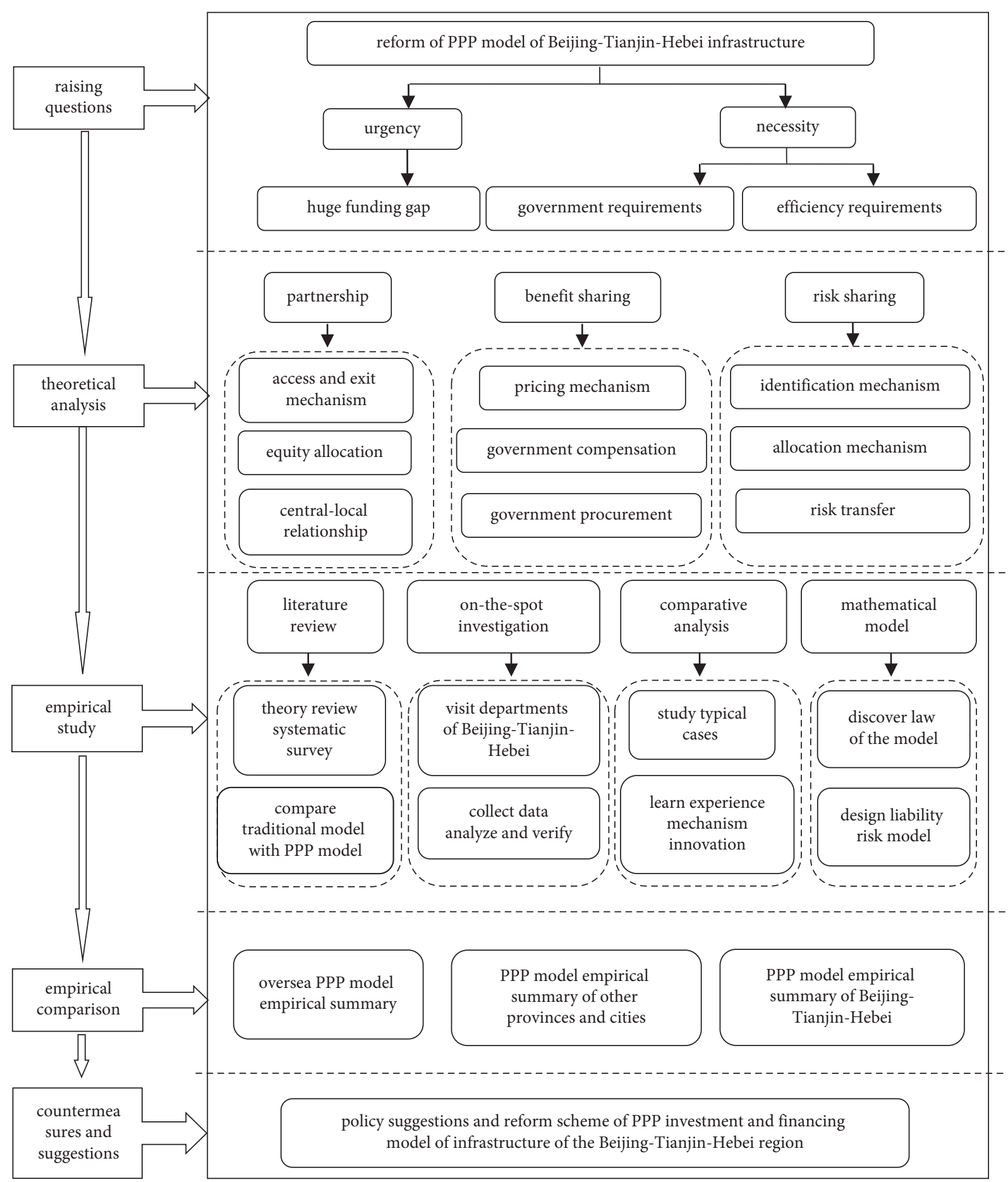

FIgURE 2: Research ideas.

risks continue to accumulate and the state continues to narrow the financing channels for local debt, this investment and financing model will not be sustainable. This research will examine the characteristics of investment and financing and internalize them into the theoretical model and empirical analysis (see Figure 2).

(3) The research is multidisciplinary. The basic model of the study comes from the PPP model, which mainly examines the benefit sharing and risk sharing in infrastructure construction from the perspective of efficiency. Considering that those management systems, investment and financing systems, and construction laws will also affect efficiency [51], this research will absorb the viewpoints and content of institutional economics, management and organizational economics, and legal theory on the PPP model. In this way, multidisciplinary research is well carried out. 
(4) Expansion of PPP investment and financing model: based on the standard PPP investment and financing model, the study analyzes the need to innovate the Beijing-Tianjin-Hebei infrastructure investment and financing system and mechanism from the perspective of academic and practical needs [52]. At the same time, the study points out that developing the PPP investment and financing model is an inevitable choice for Beijing-Tianjin-Hebei infrastructure investment and financing and puts forward practical and feasible suggestions on policy.

(5) Expansion of the scope of empirical testing: the research manages to carry out more advanced empirical research and expands its content based on existing empirical studies. The on-the-spot investigation has been done on the investment and financing innovation of Beijing-Tianjin-Hebei infrastructure in the context of big data. The data obtained from the on-the-spot analysis have been systematically sorted out and summarized. The research results are highly targeted and have more value in practical application $[26,53]$.

Because the infrastructure project itself is risky under the PPP model, it is necessary to work out a scientific and reasonable risk-sharing plan in the early stage of the project. This article builds a preliminary risk-sharing model in the TOPSIS method and other methods [54]. It proves that the model can efficiently and effectively achieve risk sharing and better solve the problem of the common risk sharing that is urgent and difficult to solve in the early stage of the project. Through the empirical research, the relevant conclusions and recommendations are finally reached through specific practices.

In recent years, the investment and financing model supported by land finance, state-owned investment and financing platforms as the main body and government investment, bank loans, and debt financing as the primary methods has promoted the rapid development of infrastructure construction in the Beijing-Tianjin-Hebei region. However, with the accumulative risks of local debt and the narrowing down of the national financing channels for local debt, this investment and financing model will not be sustainable. (1) The Beijing-Tianjin-Hebei infrastructure investment and financing method based on government investment, bank loans, and debt financing is unsustainable.

Introducing social capital into infrastructure investment and financing is a strategic requirement put forward by the 19th National Congress of the Communist Party of China. (2) The market-oriented infrastructure investment and financing model is the direction of the innovation of the Beijing-Tianjin-Hebei infrastructure investment and financing system. It is also an effective means to alleviate the shortage of infrastructure funds in the Beijing-Tianjin-Hebei region.

The investment and financing model will also become the most important investment and financing model for the Beijing-Tianjin-Hebei infrastructure construction. (3) As a market-oriented infrastructure investment and financing model, PPP has been widely used worldwide. This model is also a type of infrastructure investment and financing model highly promoted by the State Council and the Ministry of Finance in new urbanization.

(4) The Beijing-Tianjin-Hebei region should actively promote the PPP model, accelerate the improvement of PPP-related laws and regulations, set up PPP institutions as soon as possible, select pilot projects across the province, and accumulate successful experience that can be replicated.

\section{Data Availability}

The data used to support the findings of this study are available from the corresponding author upon request.

\section{Conflicts of Interest}

The authors declare that they have no conflicts of interest.

\section{Acknowledgments}

This research was supported by the R\&D Program of Beijing Municipal Education Commission (SM201911417007).

\section{References}

[1] K. Jia, "Beijing-Tianjin-Hebei integration: government and market-optimization of implementing investment and financing support based on high-level planning and government behavior," Administrative Management Reform, vol. 10, 2019.

[2] W. Meng, "Analysis of the limiting factors in the integrated development of Beijing-Tianjin-Hebei," Modern Economic Information, vol. 16, 2020.

[3] C. Cheng, "On the impact of PPP model on county economic development," Money China (Academic Edition, vol. 01, 2016.

[4] Z. Zhang, M. Jia, and D. Wan, "Research on the model of control right allocation and its influence on cooperation efficiency under the PPP model," Journal of Management in Engineering, vol. 3, 2017.

[5] X. Tang and J. Zhou, "The feasibility of Public-Private Partnership (PPP): an analysis of urban rail transit," Academic Research, vol. 02, 2018.

[6] H. Sun, Z. Fan, and Y. Shi, "Research on the optimal ownership structure of highway projects under PPP model," Journal of Management in Engineering, vol. 1, 2017.

[7] X. Xia and Z. Zheng, "Discussion on the benefit distribution under the Public-Private Partnership (PPP) model," Urban Development Research, vol. 03, 2017.

[8] L. Hu, W. Zhang, and X. Ye, "Research on the risk identification of urban infrastructure financing based on PPP mode," Gansu Social Sciences, vol. 01, 2011.

[9] X. Qi, Z. Lv, and Q. Zhang, "Research on the participation of financial institutions in PPP projects and the strategies," Shandong Social Sciences, vol. 9, 2015.

[10] R. Sun, "Research on the risks of public infrastructure PPP project financing model based on hall three-dimensional structure," Economic Survey, vol. 6, 2010.

[11] L. Lin, Z. Liu, and K. Zhang, "Game model of PPP project risk allocation under asymmetric local conditions of participants," System Engineering Theory and Practice, vol. 8, 2013.

[12] W. Zhang, Y. Yang, and Y. Wang, "The key influencing factors of the performance of public-private partnerships-based on 
the empirical research of several transitional countries," Journal of Public Management, vol. 03, 2010.

[13] J. Yuan, C. Ji, and Q. Li, "Research on key performance indicators of PPP projects of international infrastructure construction," Industrial Technology Economics.vol. 31, no. 06, 2012.

[14] Y. Ke, S. Wang, and B. Chen, "Government incentives for private capital to participate in infrastructure PPP projects," Journal of Tsinghua University (Natural Science Edition), vol. 9, 2015.

[15] X. Wu, J. Zhou, Y. Peng, and Q. Duan, "Research on Government compensation mechanism for PPP projects based on Public-Private game," China Management Science, vol. S1, 2013.

[16] W. Wang, D. Dai, and D. Wang, "Research on the election of franchisees for the BOT project of Guangxi Laibin B power plant," Technology and Management, vol. 02, 1998.

[17] Y. Sun, "Exploration of performance evaluation methods of BOT projects," China Finance, vol. 24, 2014.

[18] Chen, "Research on decision model of concession period of public utilities BOT projects," Science and Technology Progress and Countermeasures, vol. 24, 2018.

[19] Y. Yuan, Z. Ye, K. Liang, and T. Ren, "Research on the comparison and selection methods of PPP models in transportation infrastructure projects," Transportation Research, vol. 01, 2017.

[20] D. Ji, "Financing risk management of urban infrastructure PPP project," China Market, vol. 14, 2017.

[21] N. Jin, "Dynamic risk management and supervision mechanism of PPP project," Journal of the Party School of Urumqi Municipal Committee of the Communist Party of China, vol. 03, 2015.

[22] Y. Meng, "Problems and countermeasures in the investment and financing of Infrastructure construction under the PPP model," Urban Geography, vol. 16, 2017.

[23] Q. Liu and J. Ren, "The design of government supervision system of China's PPP model," Financial Supervision, vol. 06, 2019.

[24] J. Sun and H. Shen, "Research on Government supervision in the PPP financing model of urban infrastructure construction," Building Construction, vol. 06, 2018.

[25] X. Li, "Research on the synergy effect of government and private cooperation in PPP projects," Construction Economy, vol. 12, 2018.

[26] Z. Hu, "PPP paradigm selection-taking Japan as the case study object," Public Management Journal, vol. 3, 2017.

[27] K. Jia and J. Sun, "The concept, origin, characteristics, and functions of Public-Private Partnership (PPP)," Financial Research, vol. 10, 2018.

[28] X. Li, "Risk analysis of the introduction of PPP model into China's urban infrastructure," Modern Economic Information, vol. 1, 2017.

[29] C. Chen and A. Subprasom, "Efficient risk transfer in PPP wastewater treatment projects," Utilities Policy, vol. 4, 2017.

[30] D. Cumming, "New and future research in corporate finance and governance in China and emerging markets," Emerging Markets Review, vol. 46, 2020.

[31] Maskin and Tirole, "PPP and Government expenditure limits," China Economic Report, vol. 12, 2018.

[32] S. Hammami and S. Ouhibi, "An econometric study of the impact of inflation, exchange rate and interest rate on public debt using four panels of countries," Journal of Economics \& Economic Education Research, vol. 21, 2016.
[33] D. Lai and F. Fei, "The efficiency of public-private partnership (PPP): a review," Economist, vol. 7, 2016.

[34] A. J. D. Edkins and H. J. Smyth, "Business development and bid management's role in winning a public-private partnership infrastructure projects," Engineering Project Organization Journal, vol. 6, 2016.

[35] D. Grimsey and M. K. Lewis, "Are public private partnerships value for money?" Accounting Forum, vol. 9, 2019.

[36] Hart, "Potential cost implications of contracting risks," Research in Transportation Economics, vol. 6, 2013.

[37] D. Bentz and M. Daniel, "Entire contract theory in construction," The Brief, vol. 3, 2014.

[38] D. Martimort and Pouyet, "The simple microeconomics of public-private partnerships," Journal of Public Economic Theory, vol. 1, 2018.

[39] Q. Peng, Study on National Infrastructure Investment and Financing Study, Hunan Normal University Press, Hunan, China, 2012.

[40] Y. Shi and C. Li, "Analysis of the difficulties in the reform of China's urban infrastructure investment and financing system," Journal of Central University of Finance and Economics, vol. 7, 2018.

[41] X. Tang, "The "fourth way" of public goods supply-research on PPP model," Economic Survey, vol. 1, 2016.

[42] S. Wang and Y. Ke, Franchising Project Financing (BOT, PFI and PPP), Tsinghua University Press, 2008.

[43] X. Wu, J. Zhou, Y. Peng, and Q. Duan, "Research on government compensation mechanism for PPP projects based on publicprivate game," Chinese Management Science, vol. 11, 2018.

[44] C. Hayes, Public and Private Sector Cooperation Model: Policy and Financing Principles, China Social Sciences Press, Beijing, China, 2018.

[45] Q. Zhang and C. Yan, Selection of the Urban Public Infrastructure Investment and Financing, China Financial Publishing House, Haidian China, 2018.

[46] Q. Zhang, Ke Hong, and Y. Li, "Research on the innovation of infrastructure investment and financing system in Hunan province," Economic Geography, vol. 8, 2017.

[47] Z. Zhang, D. Wan, and M. Jia, "PPP three-level definition and contract characteristics," Soft Science, vol. 1, 2018.

[48] Q. Zhao, Y. Yang, Bi Zhao, and H. Sun, "A comparative study of local Government investment and financing model," Economic Research, vol. 10, 2017.

[49] C. Harris, "Private Participation in Infrastructure in Developing Countries," World Bank Working Paper, vol. 5, 2018.

[50] International Monetary Fund, Public-Private Partnerships, Fiscal Affairs Department, International Monetary Fund, Washington, DC, USA, 2018.

[51] H. Reinhard and M. Schmidt, "Public-private partnerships (PPP) in financial development in south-east Europe," in Proceedings of the Forthcoming in the Proceedings Volume of the 2013 KFW Development Finance Conference in Berlin, Springer, Berlin, Germany, 2015.

[52] P. Lam, "A sectoral review of risks associated with major infrastructure projects," International Journal of Project Management, vol. 17, no. 2, pp. 77-87, 1999.

[53] C. Parkan and M. L. Wu, "On the equivalence of operational performance measurement and multiple attribute decision making," International Journal of Production Research, vol. 35, no. 11, pp. 2963-2988, 2007.

[54] H. Deng, C.-H. Yeh, and R. J. Willis, "Inter-company comparison using modified TOPSIS with objective weights," Computers \& Operations Research, vol. 27, no. 10, pp. 963973, 2000. 